[Radiocarbon, Vol 22, No. 3, 1980, P 778-781]

\title{
THE CLIMATIC HISTORY OF THE EASTERN MEDITERRANEAN AS RECORDED IN MOLLUSK SHELLS
}

\author{
AARON KAUFMAN and MORDECKAI MAGARITZ \\ Weizmann Institute of Science, Rehovot, Israel
}

ABSTRACT. An ${ }^{18} \mathrm{O} /{ }^{16} \mathrm{O}$ versus ${ }^{14} \mathrm{C}$ age curve was constructed for unrecrystallized Holocene marine shell samples from Israel that were shown to be homogeneous populations. The surprisingly large variation in the oxygen isotopic composition $(1.2 \%)$ between 2600 and 4000 years ago is most probably due to variations in the isotopic composition of the water. This implies that either the excess of evaporation over precipitation or the Nile river discharge must have varied significantly during the Holocene.

\section{INTRODUCTION}

Shells of the marine pelecypod, Glycimeris violacescens $(\mathrm{Gv})$, are found in large quantities along most of the Israeli coast. They are exposed in heaps on the present and former shores and are buried in offshore and coastal sands and in archaeologic sites. The animal lives up to 20 years, burrowing in sand beneath the sea at 30 to $50 \mathrm{~m}$ water depths.

Preliminary measurements (Magaritz and Kaufman, 1973) showed that although the shells were all from the Holocene, they had a large range of ${ }^{18} \mathrm{O} /{ }^{16} \mathrm{O}$. By contrast, live specimens have a narrow spread that corresponds to the mean temperature of local sea water $(\mathrm{T})$ and to its $\delta^{18} \mathrm{O}(\mathrm{A})$ according to Epstein and others (1953) equation:

$$
\mathrm{T}=16.5-4.2(\delta-\mathrm{A})+0.14(\delta-\mathrm{A})^{2}
$$

Emiliani and others (1963) analyzed samples of two other pelecypods of similar age in Libya and Italy and attributed their $\delta^{18} \mathrm{O}$ variations to a $2^{\circ} \mathrm{C}$ temperature fluctuation. The present study proposed to use shells in reconstructing the East Mediterranean climatic history of the Holocene by means of detailed $\delta^{18} \mathrm{O}$ and ${ }^{14} \mathrm{C}$ age measurements.

\section{Non-climatic factors as possible causes of $\delta^{18} \mathrm{O}$ variations}

Two sets of analyses were performed to determine whether Gv shells growing in the same general vicinity at approximately the same time could have significantly different $\delta^{18} \mathrm{O}$ 's. First, three living populations (3 to 7 specimens each) from Israel, Monaco, and England were analyzed and found to have $\delta^{18} \mathrm{O}$ 's that were identical for each population within analytical error and at values that agreed with the local T's and A's according to equation (1). Second, three separate fossil shells were each cut into 3 to 7 slices, perpendicular to the direction of growth, and all slices of any one shell had identical $\delta^{18} \mathrm{O}$ 's. These results show that the oxygen isotopic composition of a Gv shell is unlikely to be anomalous as a result of the variations usually occurring in: 1) the mean growth temperatures from year to year, 2) the exact time of birth or death of the members of an approximately contemporaneous population, and 3) the exact location in which each member of a neighborhood population lived. 


\section{RESULTS AND DISCUSSION}

Samples of $\mathrm{Gv}$ were collected for analyses from about 30 locations stretching over a $130 \mathrm{~km}$ segment of the Israeli coast from near Haifa to south of Gaza. Figure 1 plots the $\delta^{18} \mathrm{O}$ measured in each shell versus the radiocarbon age measured on the whole population. The ages were computed using the 5568-year half-life and are corrected for neither isotopic fractionation nor for changes in atmospheric ${ }^{14} \mathrm{C} /{ }^{12} \mathrm{C}$. Typical uncertainties are $0.2 \%$ in $\delta^{18} \mathrm{O}$ and 170 years in the age. Only shells found to be free of calcite were analyzed.

The first finding was that many of the shell populations have spreads in $\delta^{18} \mathrm{O}$ that are beyond the analytical uncertainty. These must represent mixed populations and their age may be a weighted mean of quite different ages. The mixing was probably caused by wave activity since heaps of shells of various ages are found in various locations on the modern beach below maximum wave level.

Though the mixed ages cannot be used to fix points in a $\delta^{18} \mathrm{O}$ versus time curve, they do place limits on where such points may fall. If a mixture of two populations of similar weight is 2000 years old, neither one can be more than about 4000 years old. Thus, the obviously higher $\delta^{18} \mathrm{O}$ values of shells 1100 to 2900 years old place a constraint on any $\delta^{18} \mathrm{O}$ versus time curve constructed. The rectangle shown for this period and for the 2900 to 5400 -year period include the two-third median points of each period and emphasize that the 2900-year age separates two fairly long intervals which differ in mean $\delta^{18} \mathrm{O}$ by about $0.6 \%$.

Since we cannot use mixed populations to construct a $\delta^{18} \mathrm{O}$ versus time curve, we shall focus our attention on the curve drawn in figure 2, which is drawn only through samples whose $\delta^{18} \mathrm{O}$ spread is consistent

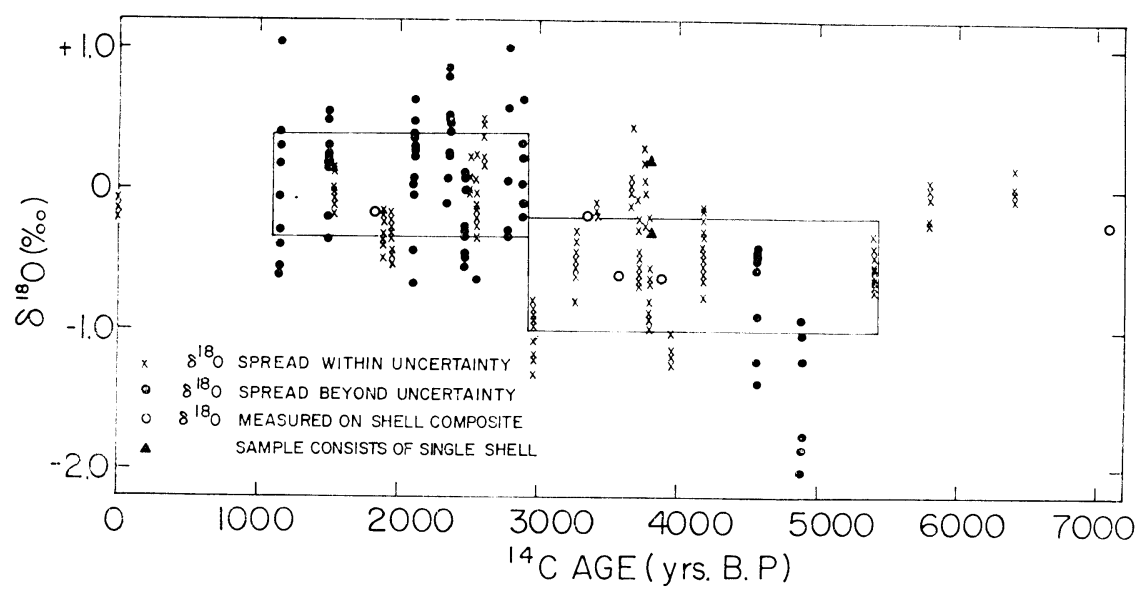

Fig 1. $\delta^{18} \mathrm{O}$ as measured on each member of a population vs the uncorrected ${ }^{14} \mathrm{C}$ age of the whole population except where indicated in the legend. The two rectangles include the two-thirds median points appearing in the age intervals 1100 to 2900 and 2900 to 5400 years ago. 
with analytical uncertainty. Though the gaps in the data and the significant analytical uncertainties permit some freedom in the drawing of the curve, the points between 2000 and 4000 years ago are relatively well fixed. Since its $\delta^{18} \mathrm{O}$ fluctuations definitely seem to have the unexpected amplitude of about $1.2 \%$, we shall discuss their meaning while the exact shape of the curve is determined with more analyses.

By equation (1), this $1.2 \%$ range in $\delta^{18} \mathrm{O}$ may be due either to a $5^{\circ} \mathrm{C}$ range in $\mathrm{T}$, to a $1.2 \%$ range in $\mathrm{A}$, or to a combination of both. Since local waters were only $4^{\circ} \mathrm{C}$ cooler than today during the glacial maximum (Thunell, 1979), the $\delta^{18} \mathrm{O}$ variations observed between 2000 and 4000 years ago must be entirely due to changes in the $\delta^{18} \mathrm{O}$ of the water.

At present, this water is mostly incoming Atlantic Ocean water $\left(\delta^{18} \mathrm{O}=+0.8\right)$ mixed with about 1.5 percent of rainfall (both direct and as river influx) whose $\delta^{18} \mathrm{O}$ is much lower. By the time the water reaches the Israeli coast, the $\delta^{18} \mathrm{O}$ increases to about +1.8 , as a result of evaporation en route. It is the excessive evaporation over precipitation that forces so much Atlantic water to enter via Gibraltar (Lacombe and Tchernia, 1972). If, in the past, this excess were smaller, the $\delta^{18} \mathrm{O}$ of the Israeli coastal water would be lower for two reasons: 1) the ratio of Atlantic water to rainwater would be lower, and 2) less evaporation would result in less ${ }^{18} \mathrm{O}$ enrichment. Thus, the more positive points in figure 2 would represent periods of greater aridity and the more negative ones, those of greater humidity.

Another possible cause for at least part of the variation seen in figure 2 involves the discharge of the Nile River which travels counterclockwise as a tongue of low-salinity water. Close monitoring during the

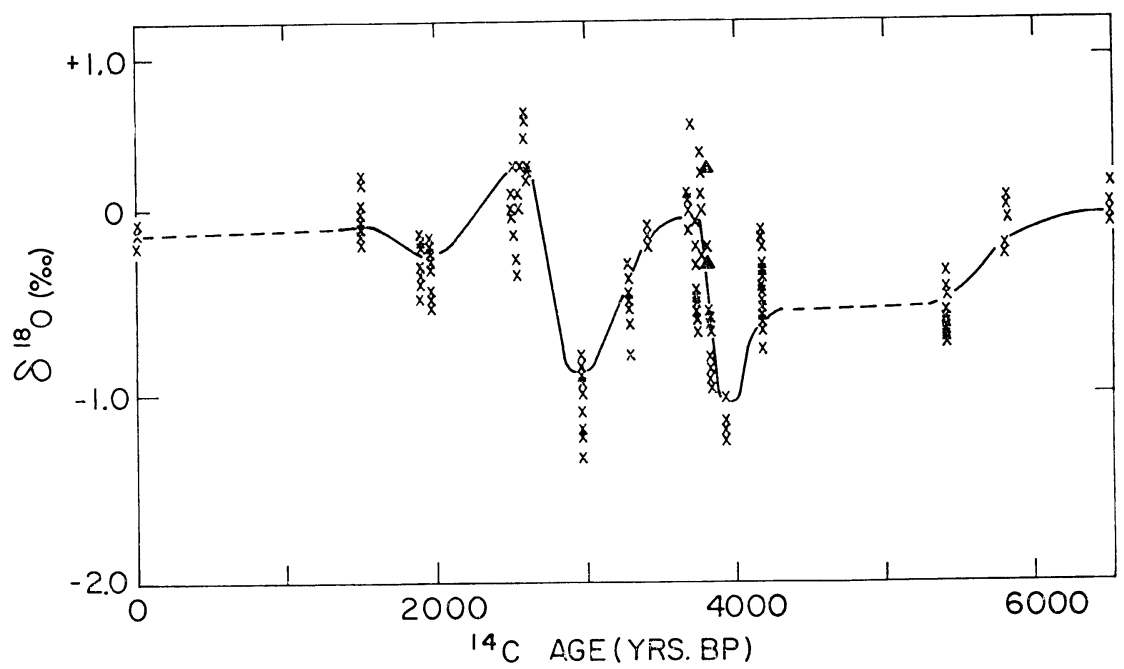

Fig 2. $\delta^{15} \mathrm{O}$ vs ${ }^{14} \mathrm{C}$ age of all the samples for which the spread in the former falls within the experimental uncertainty. The curve drawn falls within the error of each of them and is dashed where the age gaps are large. 
September flood seasons of 1947 to 1963 (Hecht, 1964) showed that the core of this tongue occurred about $6 \mathrm{~km}$ from the Israeli coast and contained up to 20 percent of fresh water (which is much lower in $\delta^{18} \mathrm{O}$ than is the surrounding saline water). Since this component was only about 5 percent in the basal water near which Gv lives and since the pulse lasts for only one month, the $\delta^{18} \mathrm{O}$ of growing shells would be affected very little. It is not impossible, however, that greater Nile discharges might have had significant effects in the past. Here, as in the above model, $\delta^{18} \mathrm{O}$ would be more positive during arid periods and more negative during humid ones. These changes, however, would refer to the climate of the East African highlands, the rainfall intensity of which determines the level of the Nile discharge.

\section{ACKNOWLEDGMENT}

This work was supported by a grant from the Israel Commission of Basic Research.

\section{REFERENCES}

Emiliani, C, Cordini, L, Mayeda, T, McBarney, C B M, and Tongiorgi, E, 1963, Paleotemperature analyses of fossil shells of marine mollusks, in Craig, Harmon, ed, Iosotopic and cosmic chemistry: Amsterdam, North Holland, p 133-156.

Epstein, S, Buchsbaum, R, Lowenstam, H A, and Urey, H C, 1953, Revised carbonatewater isotopic temperature scale: Geol Soc America Bull, v 64, p 1315-1326.

Hecht, A, 1964, On the turbulent diffusion of the water of the Nile floods in the Mediterranean Sea: Haifa, Sea Fish Research Sta, Bull 36, 24 p.

Lacombe, $\mathrm{H}$ and Tchernia, P, 1972, Caractères hydrologiques et circulation des eaux en Mediterranée, in Stanley, D J, ed, The Mediterranean Sea: Stroudsberg, Pa, Dowden Hutchinson and Ross, p 129-147.

Magaritz, Mordeckai and Kaufman, Aaron, 1973, Changes in the isotopic composition of east Mediterranean seawater during the Holocene: Nature, v 243, p 462-464.

Thuncll, R C, 1979, Eastern Mediterranean Sea during the last glacial maximum; an 18,000 years BP reconstruction: Quaternary Research, v 11, p 353-372. 